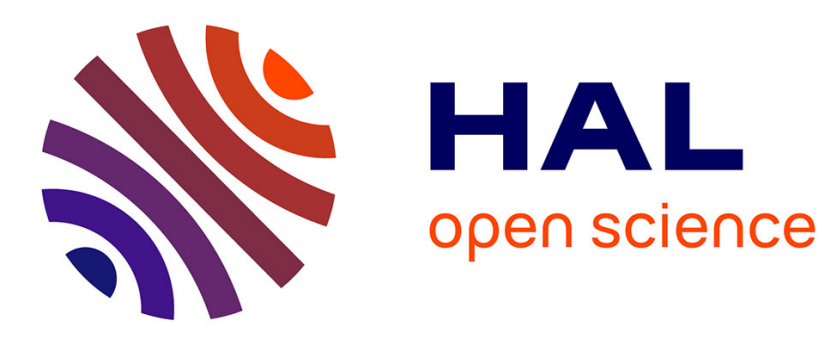

\title{
Evaluation of the tunnelling current assisted by deep traps in schottky barriers
}

Gérard Sarrabayrouse, J. Buxo, A. Myszkowski, Daniel Esteve

\section{To cite this version:}

Gérard Sarrabayrouse, J. Buxo, A. Myszkowski, Daniel Esteve. Evaluation of the tunnelling current assisted by deep traps in schottky barriers. Revue de Physique Appliquée, 1977, 12 (2), pp.433-437. 10.1051/rphysap:01977001202043300 . jpa-00244193

\section{HAL Id: jpa-00244193 https://hal.science/jpa-00244193}

Submitted on 1 Jan 1977

HAL is a multi-disciplinary open access archive for the deposit and dissemination of scientific research documents, whether they are published or not. The documents may come from teaching and research institutions in France or abroad, or from public or private research centers.
L'archive ouverte pluridisciplinaire HAL, est destinée au dépôt et à la diffusion de documents scientifiques de niveau recherche, publiés ou non, émanant des établissements d'enseignement et de recherche français ou étrangers, des laboratoires publics ou privés. 
Classification

Physics Abstracts

8.340

\title{
EVALUATION OF THE TUNNELLING CURRENT ASSISTED BY DEEP TRAPS IN SCHOTTKY BARRIERS
}

\author{
G. SARRABAYROUSE, J. BUXO, A. MYSZKOWSKI and D. ESTEVE \\ Laboratoire d'Automatique et d'Analyse des Systèmes du C. N. R. S. \\ 7, avenue du Colonel Roche, 31400 Toulouse, France
}

(Reçu le 8 mars 1976, révisé le 14 juin 1976, accepté le 4 novembre 1976)

\begin{abstract}
Résumé. - En s'appuyant sur les travaux de I. Lundström et C. Swensson relatifs au calcul des sections efficaces de capture par effet tunnel des pièges profonds, les auteurs proposent une première évaluation théorique de l'importance de la composante de courant tunnel assisté par la présence de pièges profonds dans les diodes Schottky.
\end{abstract}

Abstract. - Using the results of I. Lundström and C. Swensson for the tunneling capture crosssection of deep traps, the authors present a theoretical approach for accurately evaluating the tunneling current assisted by deep traps in Schottky diodes.

1. Introduction. - The tunneling current going through barriers containing deep traps has been discussed by several authors, among them : J. C. Penley [1], F. W. Schmidlin [2], G. H. Parker and C. A. Mead [3, 4], R. Combescot [5] and more recently by A. V. Chaplik and M. V. Entin [6]. One interesting feature of the $J(V)$ curves was already revealed by the analysis of G. H. Parker and C. A. Mead. Indeed their formalism accounts for the slope of the $J(V)$ curves that was experimentally observed at $77 \mathrm{~K}$. The description given in detail here is aimed to provide an analytical expression of the trap assisted tunneling current that contains no adjustable parameters. In the first section the physical formalism is described, the second one presents its application to the case of a Schottky barrier. The comparison between this assisted current and the direct tunneling current is carried out.

2. The physical formalism. - A potentiel barrier $U(z)$ between a metal and a semiconductor including a deep trap at distance $W$ from the metal and at energy $E_{\mathrm{L}}$ with respect to the bottom of the conduction band in the metal will be considered.

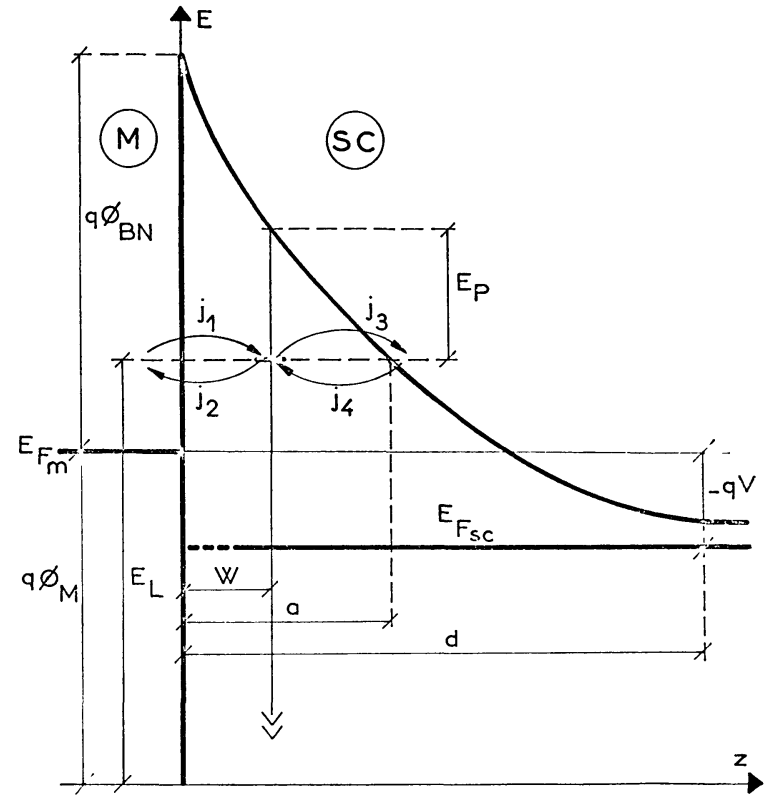

FIG. 1. - Energy diagram for the studied tunnel process.

In the $W K B$ approximation an electron coming from the metal has the following wave function for $z>0$,i. e. in the barrier :

$$
\psi_{1}(r)=2^{1 / 2} L^{-3 / 2} k_{z}\left(H_{1}^{2}(0)+k_{z}^{2}\right)^{-1 / 2} \exp \left(i k_{x} x+i k_{y} y\right) \exp \left(-\int_{0}^{z} H_{1}(t) \mathrm{d} t\right)
$$

where $L^{3}$ is the volume of the metal,

$$
\begin{gathered}
k_{x}^{2}+k_{y}^{2}+k_{z}^{2}=2 m_{1} \hbar^{-2} E_{\mathrm{L}}, \\
H^{2}(z)=2 m_{\mathrm{r}} \hbar^{-2}\left(U(z)-E_{\mathrm{L}}\right) \text {, and } H_{1}^{2}(t)=H^{2}(t)+k_{x}^{2}+k_{y}^{2} .
\end{gathered}
$$

$m_{1}$ and $m_{\mathrm{r}}$ are the effective masses of an electron respectively in the metal and in the semiconductor. 
The wave function of an electron bound to the trap represented by a Dirac delta function [7] is taken to be :

$$
\psi_{\mathrm{r}}(r)=(2 \pi)^{-1 / 2} H^{1 / 2}(W) r^{-1} \exp (-H(W) r) .
$$

Following J. Bardeen [8] and I. Lundström et al. [9] the transition probability between the metal and the trap is (see appendix) :

$$
P_{\mathrm{mp}}=2 \pi \hbar^{-1}\left|T_{\mathrm{rl}}\right|^{2} \frac{\partial n}{\partial E}
$$

with the tunneling transition matrix element :

$$
T_{\mathrm{rl}}=\int \psi_{\mathrm{r}}(r)\left(H-E_{\mathrm{L}}\right) \psi_{1}(r) \mathrm{d}^{3} r
$$

and with the density of states :

$$
\frac{\partial n}{\partial E}=\left(\frac{L}{2 \pi}\right)^{3} \frac{4 m_{1}}{\hbar^{2} k_{z}} \mathrm{~d}^{2} k_{\mathrm{p}}
$$

corresponding to the $E_{\mathrm{L}}$ energy level and to a given value of $k_{\mathrm{p}}$.

Finally, one obtains for the probability $\boldsymbol{P}_{\mathrm{mp}}$ :

$$
P_{\mathrm{mp}}=\frac{8 \hbar m_{1}}{m_{\mathrm{r}}^{2}} \int_{0}^{k_{0}} \frac{H(W) k_{z}}{H^{2}(0)+k_{0}^{2}} \exp \left[-2 \int_{0}^{W}\left(H^{2}(t)+k_{\mathrm{p}}^{2}\right)^{1 / 2} \mathrm{~d} t\right] k_{\mathrm{p}} \mathrm{d} k_{\mathrm{p}}
$$

where

$$
k_{0}^{2}=2 m_{1} \hbar^{-2} E_{\mathrm{L}}=k_{\mathrm{p}}^{2}+k_{z}^{2}
$$

The wave function of an electron coming from the semiconductor is :

$$
\psi_{1}(r)=L^{-3 / 2} k_{z}^{1 / 2} H^{-1 / 2}(z) \exp \left(i k_{x} x+i k_{y} y\right) \exp \left(-\int_{z}^{a} H_{1}(t) \mathrm{d} t\right), z<a
$$

where $a$ is the classical turning point.

The electron transition probability between the trap and the semiconductor can be obtained by the previous method leading to :

$$
P_{\mathrm{scp}}=\hbar m_{\mathrm{r}}^{-1} H(W) \int_{0}^{k_{6}}\left(H^{2}(W)+k_{\mathrm{p}}^{2}\right)^{-1 / 2} \exp \left[-2 \int_{W}^{a}\left(H^{2}(t)+k_{\mathrm{p}}^{2}\right)^{1 / 2} \mathrm{~d} t\right] k_{\mathrm{p}} \mathrm{d} k_{\mathrm{p}}
$$

where

$$
k_{0}^{\prime 2}=2 m_{\mathrm{r}} \hbar^{-2}\left(E_{\mathrm{L}}-E_{\mathrm{C}}\right)
$$

and $E_{\mathrm{C}}$ is the energy of the bottom of the semiconductor conduction band.

The detailed balance principle will now be applied in order to compute the current density carried through the trap between the metal and the semiconductor.

The current density components for the two elementary transitions can then be written in the form

$$
\begin{aligned}
& j_{\mathrm{mp}}=j_{1}-j_{2}=q N_{\mathrm{t}} P_{\mathrm{mp}}\left(f_{\mathrm{m}}-f_{\mathrm{t}}\right) \\
& j_{\mathrm{psc}}=j_{3}-j_{4}=q N_{\mathrm{t}} P_{\mathrm{scp}}\left(f_{\mathrm{t}}-f_{\mathrm{sc}}\right)
\end{aligned}
$$

where $N_{\mathrm{t}}$ is the density of traps and $f_{\mathrm{m}}, f_{\mathrm{sc}}, f_{\mathrm{t}}$ stand for the occupancy factors in respectively the metal, the semiconductor and the trap at energy $E_{\mathrm{L}}$.

In the steady state situation the equality between these two currents allows one to determine the trap occupancy $f_{\mathrm{t}}$. The tunneling current at $E_{\mathrm{L}}$ then is :

$$
j=q N_{\mathrm{t}} P\left(f_{\mathrm{m}}-f_{\mathrm{sc}}\right)
$$

with

$$
P^{-1}=P_{\mathrm{mp}}^{-1}+P_{\mathrm{scp}}^{-1}
$$


3. Application to the case of a Schottky barrier. - When expressions (6) and (8) are integrated $\left({ }^{1}\right)$ in the case of a parabolic barrier

$$
U(z)=+q^{2} \frac{N_{\mathrm{D}}(d-x)^{2}}{2 \varepsilon}-q^{2} \frac{N_{\mathrm{D}} d^{2}}{2 \varepsilon}+q \varphi_{\mathrm{BN}}+q \varphi_{\mathrm{FM}} \text { (see Fig. 1), }
$$

one obtains :

$$
\begin{gathered}
P_{\mathrm{mp}}=\frac{4 \hbar m_{1}}{m_{\mathrm{r}}^{2}} \frac{H(W) k_{0} / A}{\left(H^{2}(0)+k_{0}^{2}\right)}\left\{1-\left(A k_{0}^{2}\right)^{-1 / 2} D\left(\left(A k_{0}^{2}\right)^{1 / 2}\right)\right\} \exp -2 F \\
P_{\mathrm{scp}}=\pi^{1 / 2} \hbar m_{\mathrm{r}}^{-1} H(W)^{-1 / 2} A_{1} \exp \left(A_{1} \mathrm{H}^{2}(W)\right)\left\{\varphi\left(A_{1}^{1 / 2}\left(k_{0}+H^{2}(W)\right)^{1 / 2}\right)-\left(A_{1}^{1 / 2} H(W)\right)\right\} \exp -2 F_{1}
\end{gathered}
$$

with :

$$
\begin{aligned}
& A=\xi(d, d-W)=C^{-1 / 2} \ln \left[\eta C^{1 / 2}+\left(C \eta^{2}+R\right)^{1 / 2}\right]_{\eta=d-w}^{\eta=d} \\
& F=\chi(d, d-W)=\frac{1}{2} R \xi(d, d-W)+\left[\frac{1}{2} \eta\left(C \eta^{2}+R\right)^{1 / 2}\right]_{\eta=d-W}^{\eta=d} \\
& A_{1}=\xi(d-W, d-a) \quad F_{1}=\chi(d-W, d-a) \\
& C=q^{2} N_{\mathrm{D}} m_{\mathrm{r}} \varepsilon^{-1} \hbar^{-2} \quad D=+2 m_{\mathrm{r}} \hbar^{-2}\left(U(d)-E_{\mathrm{L}}\right)
\end{aligned}
$$

where $N_{\mathrm{D}}$ is the doping level in the semiconductor, $d$ the space charge width, $\varphi_{\mathrm{BN}}$ the barrier height and $\varphi_{\mathrm{FM}}$ the energy of the Fermi level in the metal with respect to the botton of the metal conduction band.

The most important physical features of the current corresponding to the Schottky barrier case can be made clearer using the triangular barrier approximation

$$
U(z)=-\frac{q^{2} N_{\mathrm{D}} d z}{\varepsilon}+q \varphi_{\mathrm{BN}}+q \varphi_{\mathrm{FM}}
$$

one then obtains by using Boltzmann statistics :

$$
j=2^{-1 / 2} q^{3} N_{\mathrm{D}} N_{T} \mathrm{~d} \varepsilon^{-1} m_{\mathrm{r}}^{-1 / 2} F\left(E_{\mathrm{L}}, W\right) \cdot G\left(E_{\mathrm{L}}, W\right)\left(1-e^{q V / k T}\right)
$$

with

$$
\begin{gathered}
F\left(E_{\mathrm{L}}, W\right)=\exp \left\{-\lambda\left(U(W)-E_{\mathrm{L}}\right)^{3 / 2}-E_{\mathrm{L}} / k T\right\}\left(U(W)-E_{\mathrm{L}}\right)^{-1 / 2} \\
G^{-1}\left(E_{\mathrm{L}}, W\right)=\left\{1+4 m_{\mathrm{r}}^{1 / 2} m_{1}^{-1 / 2}\left(m_{\mathrm{r}} m_{1}^{-1} \theta+E_{\mathrm{L}}\right)\left(\theta^{1 / 2}-\Omega^{1 / 2}\right) \Omega^{-1} E_{\mathrm{L}}^{-1 / 2} \exp -\lambda\left(\theta^{3 / 2}-2 \Omega^{3 / 2}\right)\right\}
\end{gathered}
$$

and

$$
\lambda=\frac{4}{3}\left(2 m_{\mathrm{r}} \hbar^{-2}\right)^{1 / 2}, \quad \varepsilon q^{-2} N_{\mathrm{D}}^{-1} d^{-1}, \quad \theta=U(0)-E_{\mathrm{L}}, \quad \Omega=U(W)-E_{\mathrm{L}}
$$

It appears that $j$ presents a double maximum value depending on both $E_{\mathrm{L}}$ and $W$. This is due to the fact that, on the one hand, $P$ grows with the increasing values of $E_{\mathrm{L}}$ whereas both $f_{\mathrm{m}}$ and $f_{\mathrm{sc}}$ decrease ; the value of $E_{\mathrm{L}}$ corresponding to this maximum is called $E_{\mathrm{M}}$. On the other hand $j$ passes through another maximum for the particular value $W_{\mathrm{M}}$ where $P_{\mathrm{mp}}=P_{\text {scp }}$.

The expressions (15) and (14) respectively allow one to calculate $E_{\mathrm{M}}$ and $W_{\mathrm{M}}$. The expressions :

$$
\begin{aligned}
& E_{\mathrm{M}}=\left[2^{2 / 3} U(W)-U(0)\right]\left(2^{2 / 3}-1\right)^{-1} \\
& W_{\mathrm{M}}=2^{-5 / 3}\left(2^{2 / 3}-1\right) \hbar^{2} q^{2} N_{\mathrm{D}} \mathrm{d} m_{\mathrm{r}}^{-1}(k T)^{-2}
\end{aligned}
$$

provide good approximations for these two values. The current at this maximum is then given by :

$$
j=2^{1 / 3} q N_{\mathrm{t}} \hbar^{-1} k T\left(1-\mathrm{e}^{q V / k T}\right) \text { e } \frac{-q \varphi_{\mathrm{BN}}}{k T} \exp \left[\frac{1}{6}\left(\hbar q^{2} N_{\mathrm{D}} \mathrm{d} m_{\mathrm{r}}^{-1 / 2} \varepsilon^{-1}(k T)^{-3 / 2}\right)^{2}\right] \text {. }
$$

(1) The exponential is a rapidly decreasing function of $k_{\mathrm{p}}$ and only the first two terms in the development of its argument will be considered. 
This current is compared to the direct tunneling current $J_{\mathrm{T}}$, also going through the barrier [10], on figure 2. This figure directly provides on the $y$-axis the value of the trap density $N_{\mathrm{t}}$, for which $j$ equals $J_{\mathbf{T}}$

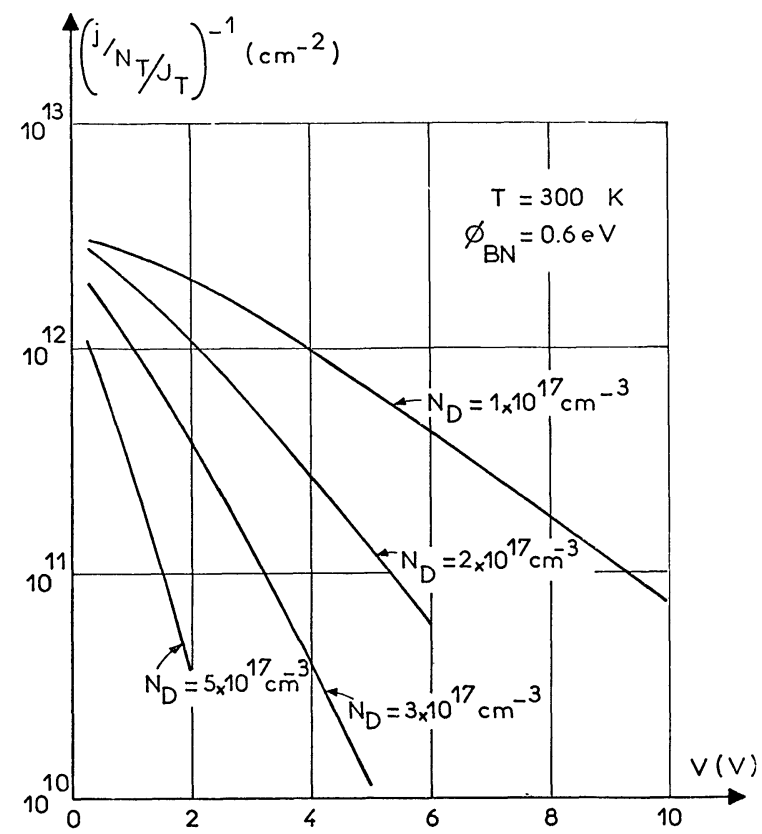

Fig. 2. - Comparison between the trap assisted tunneling current and the direct tunneling current (in the range where Boltzman statistics applies).

and corresponds to the case of a reversely biased metal-silicon Schottky barrier at room temperature for which the value $\varphi_{\mathrm{BN}}=0.6 \mathrm{eV}$ has been assumed. The values of $W_{\mathrm{M}}$ given by (17) appear then to be comprised in the following ranges : $5 \AA<W_{\mathrm{M}}<100 \AA$ for $10^{17} \mathrm{~cm}^{3}<N_{\mathrm{D}}<5 \times 10^{17} \mathrm{~cm}^{3}$ and $0<V<10 \mathrm{~V}$.

This result shows that the occurence of this trap assisted current in a reversely biased Schottky barrier is far from being unlikely. Indeed, recent backscattering measurements carried out by A. Martinez [11] show that, after standard stabilizing annealing treatments, a large density of metallic centres can be present over distances as large as $500 \AA$ of the metallic interface.

The present theory can then account for the large values of the reverse currents in these barriers that have not been clearly explained up to now.

Appendix. - It will be now shown that Bardeen's method [8] can be applied to calculate either $P_{\mathrm{mp}}$ or $P_{\text {scp. }}$.

The trap is assumed to be well described by a short range potentiel $V_{\mathrm{p}}$ containing a simple bound state; as we are here neglecting the direct tunneling current we shall assume that $\psi_{1}$ only contains its decreasing component. If the trap is located far away enough from the boundary, the overlap between $\psi_{1}$ and $\psi_{\mathrm{r}}$ is small and the total wave function of the fundamental state of the system is well approximated by :

$$
\begin{aligned}
& \psi(r, t)=a(t) \psi_{1}(r) \exp \left(-\frac{i E_{1} t}{\hbar}\right)+ \\
&+b(t) \psi_{\mathrm{r}}(r) \exp \left(-\frac{i E_{\mathrm{r}} t}{\hbar}\right)
\end{aligned}
$$

where $E_{1}$ and $E_{\mathrm{r}}$ are respectively the energies corresponding to $\psi_{1}$ and $\psi_{\mathrm{r}}$. It is now assumed that at time $t=0$ the electron is in the state $\psi_{1}$ so that $a(0)=1$ and $b(0)=0$. The Schodinger equation integrated over the barrier volume $V$ with $\psi_{\mathrm{r}}(r)$ or $\psi_{1}(r)$ leads to :

$$
\frac{\mathrm{d} b}{\mathrm{~d} t}=\frac{1}{i \hbar} \exp \left[\frac{i t}{\hbar}\left(E_{\mathrm{r}}-E_{1}\right)\right] T_{\mathrm{rl}}
$$

with

$$
T_{\mathrm{rl}}=\int_{V} \psi_{\mathrm{r}}(r)\left(H_{0}+V_{\mathrm{p}}-E_{1}\right) \psi_{1}(r) \mathrm{d}^{3} r
$$

It is assumed that for a trap inside the barrier :

$$
\int_{V}\left|\psi_{\mathrm{r}}\right|^{2} \mathrm{~d}^{3} r \approx 1
$$

The integration over the time variable in (A.2) allows one to obtain $b(t)$. The current corresponding to the wave function (A. 1) is then given by :

$j=\hbar m^{-1} T_{\mathrm{r} 1}\left(E_{\mathrm{r}}-E_{1}\right)^{-1} \sin \left[t\left(E_{\mathrm{r}}-E_{1}\right) / \hbar\right] \times$

In order to obtain the transition probability we integrate this current over the surface of the boundary. (As the barrier volume is very large this integral can be transformed in an integral over the barrier volume with the help of the Gauss theorem.) This leads to :

$$
J=\frac{2}{\hbar}\left|T_{\mathrm{r} 1}\right|^{2}\left(E_{\mathrm{r}}-E_{1}\right)^{-1} \sin \left[t\left(E_{\mathrm{r}}-E_{1}\right) / \hbar\right] .
$$

The averaged probability is then given by :

$$
P=\lim _{t \rightarrow \infty} t^{-1} \int_{0}^{t}|J| \mathrm{d} t=\frac{2 \pi}{\hbar}\left|T_{\mathrm{rl}}\right|^{2} . \delta\left(E_{\mathrm{r}}-E_{1}\right) .
$$

This formula has been used by I. Lundström and C. Swensson [9]. As we do not use here particular forms of $\psi_{\mathrm{r}}$ and $\psi_{1}$ it remains valid for any barrier and any short range trap potential if the trap is located sufficiently far away from the barrier boundary. This condition is satisfied in almost all the situations of the problem treated here. 


\section{References}

[1] Penley, J. C., Phys. Rev. 128 (1962).

[2] Schmidlin, F. W., J. Appl. Phys. 37 (1966).

[3] Parker, G. H. and Mead, C. A., Appl. Phys. Lett. 14 (1969) 21.

[4] Parker, G. H. and Mead, C. A., Phys. Rev. 184 (1969) 780.

[5] Combescot, R., J. Phys. C., 4 (1971) 2611.

[6] Chaplik, A. V. and Entin, M. V., Sov. Phys. JETP 40 (1974) 106.
[7] Lucowsky, G., Solid State Commun. 3 (1965) 299.

[8] Bardeen, J., Phys. Rev. Lett. 6 (1961) 57.

[9] Lundström, I. and Swensson, C., J. Appl. Phys. 43 (1972) 5045.

[10] Padovani, F. A. and Stratton, R., Solid State Elect. 9 (1966) 695

[11] Martinez, A., Thesis, P. Sabatier University Toulouse, $n^{\circ} 704$ (1976) 